MATEC Web of Conferences 28, 02001 (2015)

DOI: $10.1051 /$ matecconf $/ 20152802001$

(C) Owned by the authors, published by EDP Sciences, 2015

\title{
In-Process Chatter Detection in Surface Grinding
}

\author{
Somkiat Tangjitsitcharoen ${ }^{1, a}$ and Angsumalin Senjuntichai ${ }^{2}$ \\ ${ }^{1,2}$ Department of Industrial Engineering, Faculty of Engineering, Chulalongkorn University \\ Phayathai Road, Patumwan, Bangkok, 10330, Thailand
}

\begin{abstract}
The chatter causes the poor surface finish during the surface grinding. It is therefore necessary to monitor the chatter during the process. Hence, this research has proposed the in-process chatter detection in the surface grinding process by utilizing the dynamic cutting forces. The ratios of the average variances of three dynamic cutting forces have been adopted and applied to identify the chatter during the surface grinding process to eliminate the effects of the cutting conditions. The effects of the cutting conditions on the chatter are also studied and analyzed. The algorithm has been proposed to detect the chatter regardless of the cutting conditions. The verification of the proposed system has been proved through another experiment by using the new cutting conditions. The experimental results have run satisfaction. It is understood that the chatter can be avoided during the in-process surface grinding even though the cutting conditions are changed.
\end{abstract}

\section{Introduction}

In the manufacturing society nowadays, the present trend is really changed from the former time. Many industries have been trying to use the intelligent machine in order to increase the process capability. It plays an important role gradually in the manufacturing process in several industries such as the automotive industry and the mold industry. Hence, the intelligent machine, which can detect and avoid the unwanted cutting states during the cutting process, is expected to be realized soon in the manufacturing industry.

The surface grinding process is one of the important processes to produce the better surface finish of the machining parts. However, the chatter is the major limitation of surface finish which can occur during the grinding process. Hence, the in-process chatter detection is expected to be realized in order to avoid the chatter and achieve the intelligent machine in the near future. If the chatter appears, the surface grinding process will be unstable and the expected surface finish might be unacceptable, which leads to the reject and the low productivity. Hence, it is required to eliminate the chatter while the surface grinding.

The sensors and the methodologies to detect chatter have been devoted so far [1-3]. The types of sensors, which are appropriate for applying with the grinding process, are the force sensor, the acceleration sensor and the acoustic emission sensor [4-7]. The cutting force signals have been carried out from the other points of views [8-10]. The analysis of cutting force, has been presented in recent papers to detect cutting states [11, 12]. The artificial neutral networks and clustering techniques have been employed by many researches but the preliminary experiments for specific cases are always required to train the system [13]. A simplified method for recognizing the cutting states has been proposed by utilizing the dynamic components of cutting forces [14, 15]. The chatter can be effectively avoided in real time using the ratios of the average variances of three dynamic cutting forces $[14,16]$.

Hence, the aim of this research is to develop an inprocess chatter detection in the grinding process by calculating the average variances of dynamic cutting forces, which has been proposed to detect the chatter in many cutting processes of the author $[11,14,16]$.

\section{Relation between Chatter and Dynamic Cutting Forces}

The amplitudes of the dynamic cutting forces (which are $\mathrm{F}_{\mathrm{X}}$ : feed force, $\mathrm{F}_{\mathrm{y}}$ : tangential force, and $\mathrm{F}_{\mathrm{z}}$ : normal force) of $\mathrm{F}_{\mathrm{y}}$ and $\mathrm{F}_{\mathrm{z}}$ are expected to be larger than the one of $F_{x}$ while the chatter appears. However, the generation of chatter affects mostly the tangential force in the cutting speed direction $[11,17]$. The preliminary experiments have been conducted in this research by employing the steel AISI 1050 with the white alumina oxide grinding wheel to check the chatter frequency.

The preliminary experimental results showed that the vibration of the grinding wheel occurs at $4.7 \mathrm{kHz}$ as shown in Fig. 1. The spindle speed of the grinding wheel is running at 3,300 rpm. However, the chatter frequency will disappear during the normal grinding process or which is the nonchatter state as shown in Fig. 2.

${ }^{a}$ Corresponding author email: somkiat.t@eng.chula.ac.th 

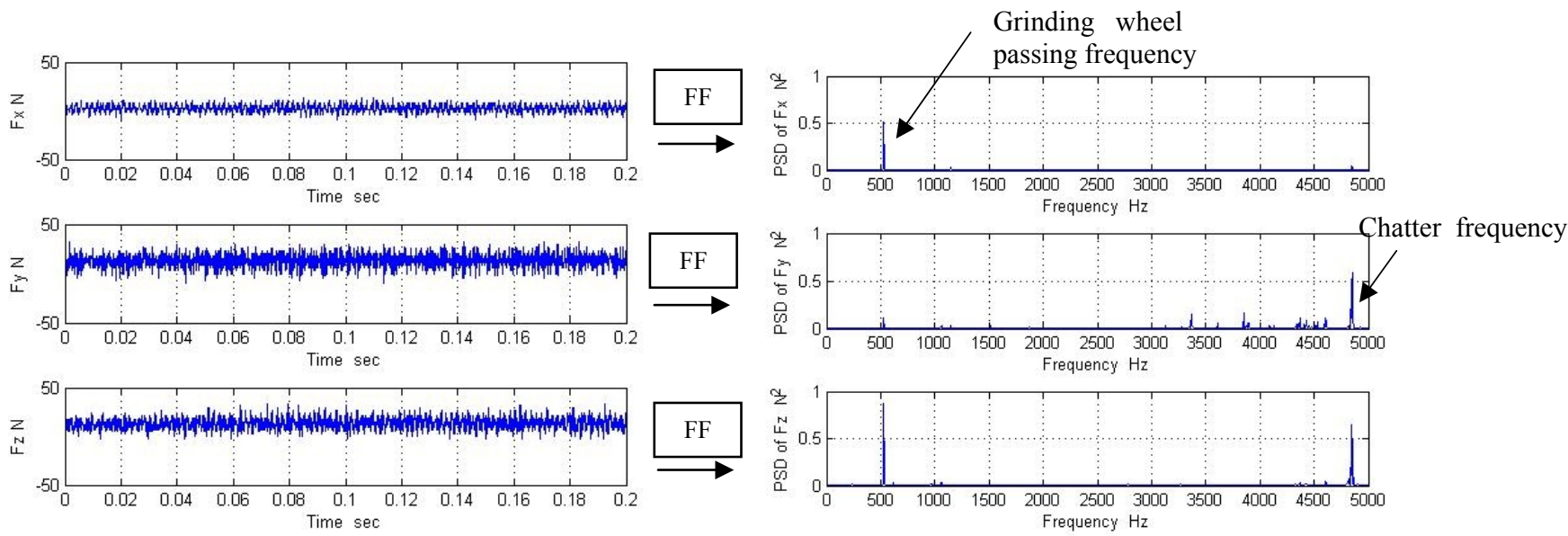

Figure 1. Illustration of the dynamic cutting forces and their FFT in grinding process; Chatter: spindle speed $=3,300 \mathrm{rpm}$, feed rate $=$ $33 \mathrm{~mm} / \mathrm{s}$, depth of cut $=0.025 \mathrm{~mm}$.
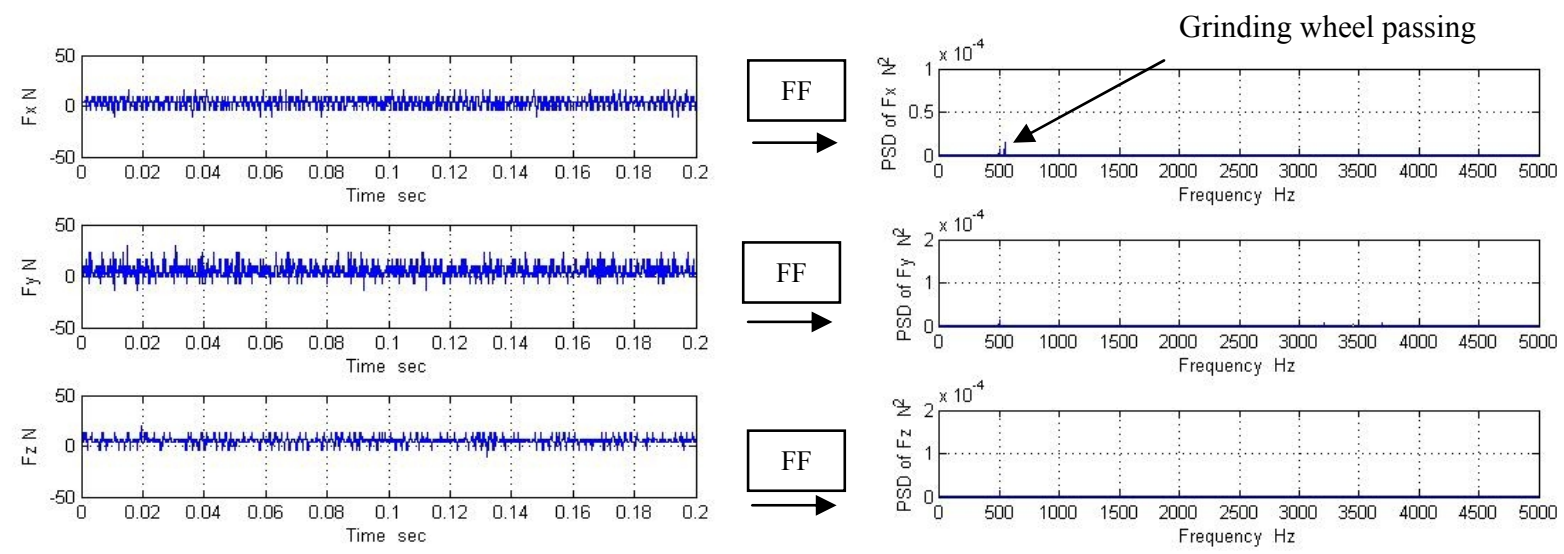

Figure 2. Illustration of dynamic cutting forces and their FFT in grinding process; Nonchatter: spindle speed $=3,300 \mathrm{rpm}$, feed rate $=33 \mathrm{~mm} / \mathrm{s}$, depth of cut $=0.005 \mathrm{~mm}$.

\section{Ratios of Average Variances of Dynamic Cutting Forces}

The previously proposed method of the author is adopted $[14,16]$ to classify the chatter and the nonchatter. The average variances of dynamic cutting forces are calculated during the in-process grinding as shown in Fig. 3.

The average variances of the dynamic cutting forces are generalized to detect the chatter in the grinding process by taking the ratio of their corresponding time records of them $\left(\frac{X}{Y}, \frac{X}{Z}, \frac{Y}{Z}\right)$. Hence, the method introduces three parameters $\left(\mathrm{G} 1=\frac{\mathrm{X}}{\mathrm{Y}}, \mathrm{G} 2=\frac{\mathrm{X}}{\mathrm{Z}}, \mathrm{G} 3=\frac{\mathrm{Y}}{\mathrm{Z}}\right)$ to cut off the effects of cutting conditions from those cutting forces even though the cutting conditions are changed as shown in Fig. 3.

The values of G1 and G2 are expected to be lower while the chatter happens due to the relatively large in amplitudes of $Y$ and $Z$. However, the values of G3 are supposed to be higher either the chatter or the nonchatter appears. Since the amplitude of $Y$ occurs in the same direction of the cutting speed, which results in the largest dynamic cutting forces.

Hence, the suitable values of G1, G2, and G3 can be determined and the chatter can be identified even though the cutting conditions have been changed.

The following procedures and the flowchart [16] are adopted to calculate the relation between the parameters (G1, G2, and G3) and the chatter during the grinding process as shown in Fig. 4.

1. Start cutting under the various cutting conditions and measure the dynamic cutting forces $\left(\mathrm{F}_{\mathrm{x}}, \mathrm{F}_{\mathrm{y}}\right.$, and $\left.\mathrm{F}_{\mathrm{z}}\right)$ for 0.2 seconds with the repetition of three times for each cutting condition.

2. Calculate the average variances of dynamic cutting forces $\left(X=X_{1}-X_{2}, Y=Y_{1}-Y_{2}, Z=Z_{1}-Z_{2}\right)$. 
3. Take ratios of those average variances of the dynamic cutting forces, $\mathrm{G} 1=\frac{\mathrm{X}}{\mathrm{Y}}, \mathrm{G} 2=\frac{\mathrm{X}}{\mathrm{Z}}, \mathrm{G} 3=\frac{\mathrm{Y}}{\mathrm{Z}}$. 4. Repeat procedures 1 to 3 for other cutting conditions.

5. Examine the relations of $G_{1}, G_{2}$ and $G_{3}$ for the chatter.
6. Determine the suitable values of $G_{1}, G_{2}$ and $G_{3}$ which are $T_{1}, T_{2}$, and $T_{3}$, respectively to detect the chatter.

7. Propose the algorithm to avoid the chatter and verify the determined values $\mathrm{T}_{1}, \mathrm{~T}_{2}$, and $\mathrm{T}_{3}$ by employing the new cutting tests.
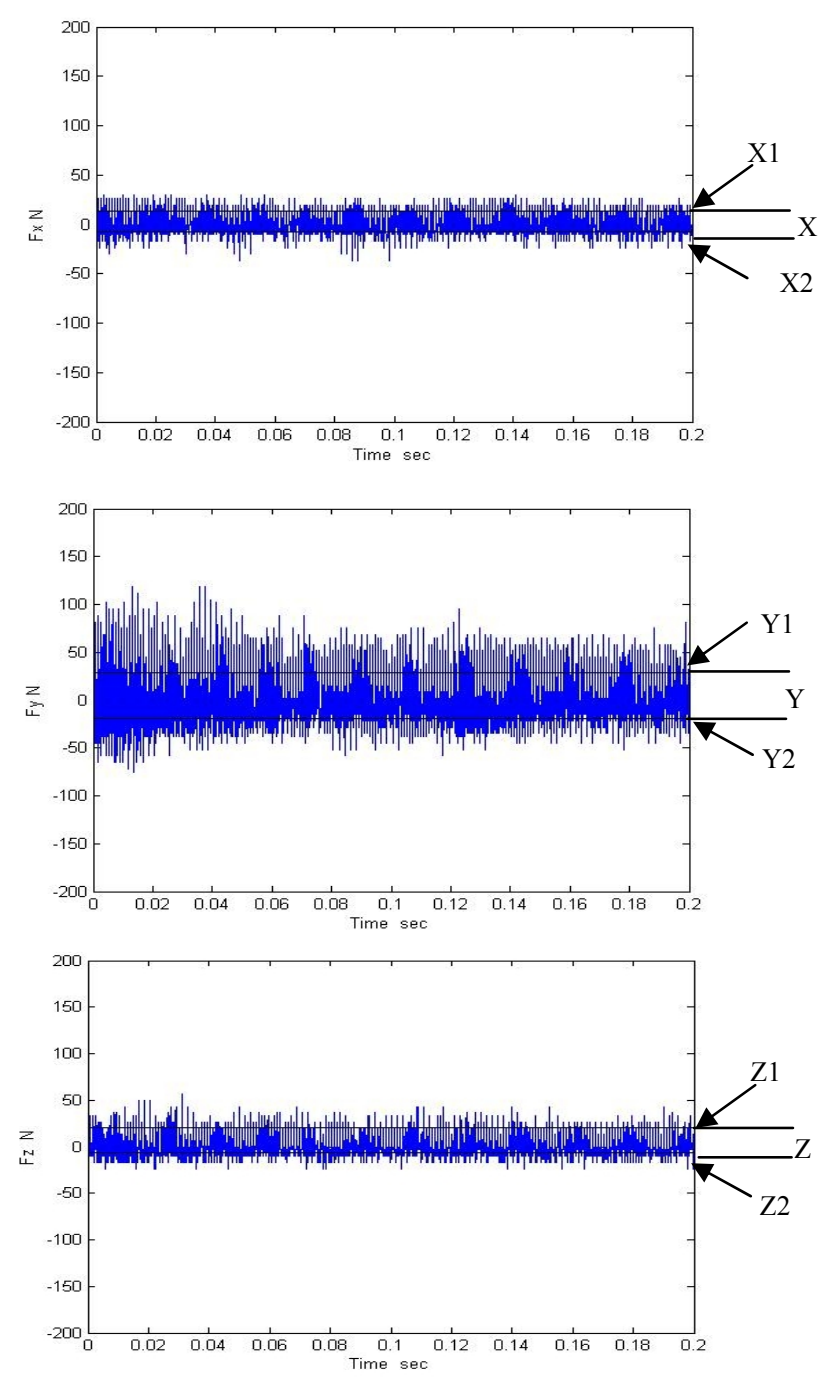

$$
\mathrm{G} 1=\mathrm{X} / \mathrm{Y}, \mathrm{G} 2=\mathrm{X} / \mathrm{Z}, \mathrm{G} 3=\mathrm{Y} / \mathrm{Z}
$$

Figure 3. Illustration of the average variances of dynamic cutting forces (X, Y, and Z); Cutting condition: spindle speed $=6,600 \mathrm{rpm}$, feed rate $=33 \mathrm{~mm} / \mathrm{s}$, depth of cut $=0.005 \mathrm{~mm}$. 


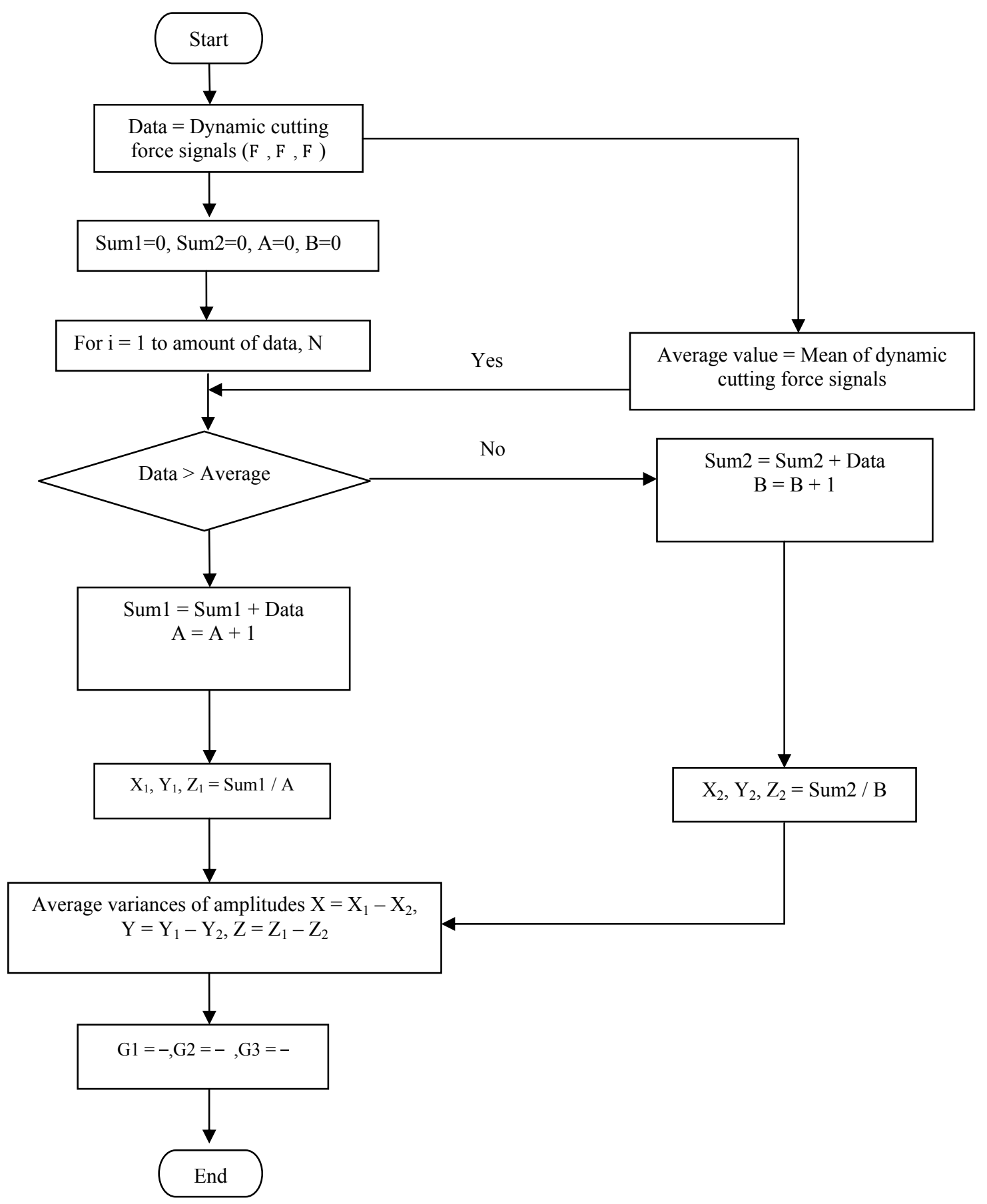

Figure 4. Flowchart to calculate the parameters of G1, G2, and G3.

\section{Experimental Setup and Procedures}

The surface grinding experiments are conducted with the use of white alumina oxide wheel. The commercial grinding machine is employed for the experiments. The workpiece is carbon steel (AISI 1050) with the size of 64 x 64 x $45 \mathrm{~mm}^{3}$. The dynamometer (Kistler 9257B) has been installed onto the table of the grinding machine as shown in Fig. 5.

The major grinding conditions are summarized in Table 1 to obtain the reference feature spaces and the suitable values (T1, T2, and T3) for chatter detection. The dynamic cutting force components detected by the tool dynamometer are amplified and low-pass filtered with the cut off frequency of $5 \mathrm{kHz}$ prior to digitization and calculation within PC. The sampling rate is $10 \mathrm{kHz}$. However, it is proven that the chatter frequency of the grinding wheel is about $4.7 \mathrm{kHz}$. Hence, the dynamic cutting forces are well detected by the dynamometer during the surface grinding process.

Table 1. Major cutting conditions.

\begin{tabular}{|c|c|c|}
\hline Workpiece & \multicolumn{2}{|c|}{ S50C carbon steel } \\
\hline Grinding wheel & \multicolumn{2}{|c|}{ White alumina oxide wheel } \\
\hline Spindle Speed (rpm) & 6,600 & 3,300 \\
\hline Depth of cut (mm) & \multicolumn{2}{|c|}{$0.005,0.01,0.015,0.02,0.025$} \\
\hline Feed rate $(\mathrm{mm} / \mathrm{sec})$ & \multicolumn{2}{|c|}{$55,44,33,22$} \\
\hline
\end{tabular}




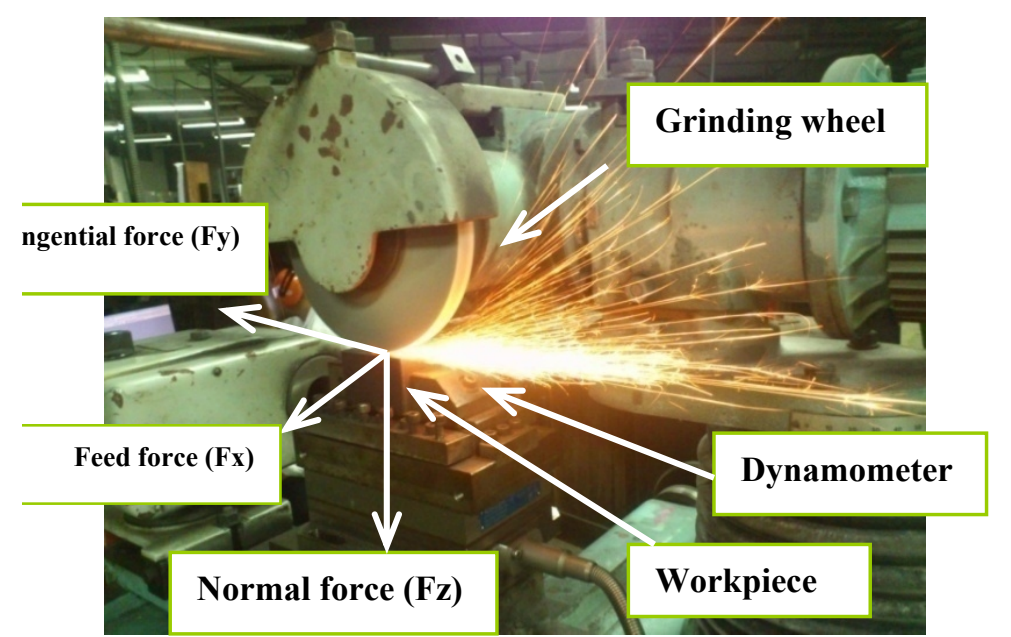

Figure 5. Illustration of experimental setup.

\section{Experimental Results Discussions}

The series of cutting tests were carried out under the major cutting conditions mentioned above, and the dynamic cutting forces were measured during the surface grinding process. Fig. 6 shows the experimentally obtained dynamic cutting forces between the chatter and the nonchatter. It is understand that the amplitudes of $\mathrm{F}_{\mathrm{y}}$ and $\mathrm{F}_{\mathrm{z}}$ are relatively large while the chatter happens.

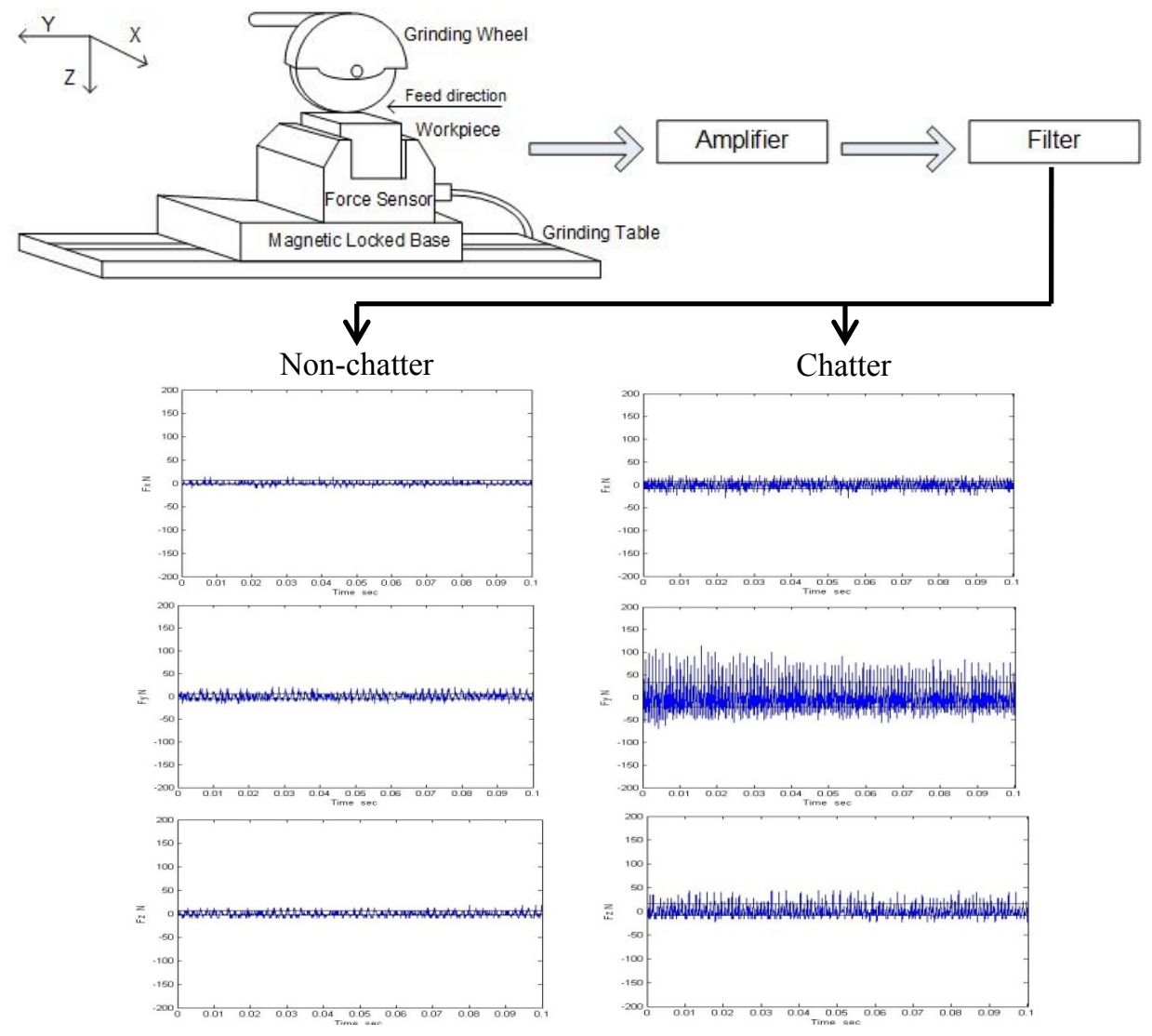

Figure 6. Illustration of experimentally obtained dynamic cutting forces during grinding process;

Nonchatter: spindle speed $=3,300 \mathrm{rpm}$, feed rate $=55 \mathrm{~mm} / \mathrm{s}$, depth of cut $=0.005 \mathrm{~mm}$.

Chatter: spindle speed $=6,600 \mathrm{rpm}$, feed rate $=55 \mathrm{~mm} / \mathrm{s}$, depth of cut $=0.025 \mathrm{~mm}$.

\section{Classification of Chatter}

Figs. 7 to 9 illustrated the experimentally obtained relations of $\mathrm{G} 1$ and $\mathrm{G} 2, \mathrm{G} 1$ and $\mathrm{G} 3, \mathrm{G} 2$ and $\mathrm{G} 3$, respectively. The values of the parameters G1 and G2 are relatively high when the nonchatter appears as shown in Figs 7 to 9. It is understood that the average variances of the dynamic cutting force of $F_{X}$ is smaller than the ones of $\mathrm{F}_{\mathrm{y}}$ and $\mathrm{F}_{\mathrm{z}}$.

According to Figs 7 to 9 , the suitable values of $G_{1}$, $G_{2}$ and $G_{3}$ can be determined to classify the chatter and the nonchatter.
Hence, the proper values of T1, T2, and T3 are predefined here as $0.6,0.8$ and 0.9 , respectively. The chatter can be detected during the in-process grinding regardless of the cutting conditions by mapping the experimentally obtained values of parameters G1, G2 and G3 into the reference feature spaces as shown in Figs 7 to 9 referring to the determined critical values of $\mathrm{T} 1, \mathrm{~T} 2$ and T3. It is hence concluded that the chatter can be detected when the parameter values of G1 and $\mathrm{G} 2$ are less than the critical values of $\mathrm{T} 1$ and $\mathrm{T} 2$ while the parameter value of $\mathrm{G} 3$ exceeds the critical value of $\mathrm{T} 3$, respectively. The three-dimensional reference feature space of the parameters G1, G2, and G3 is hence obtained as shown in Fig. 10. 


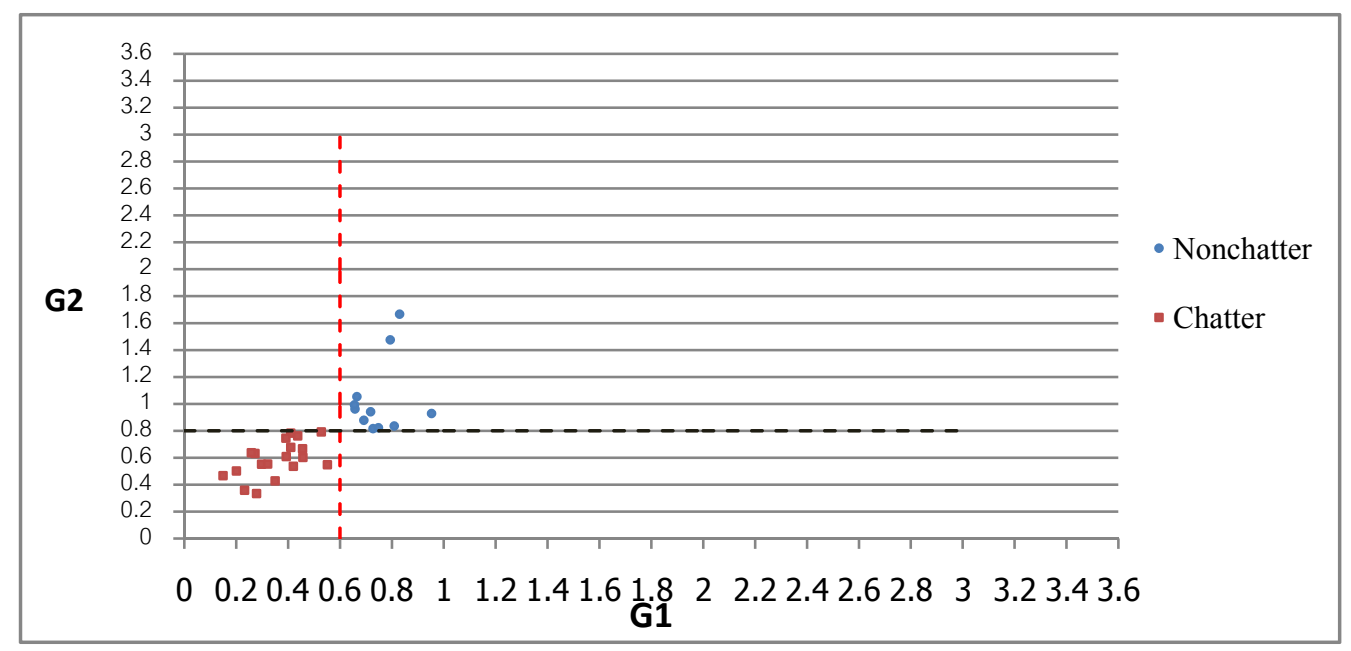

Figure 7. Illustration of the experimentally obtained relation between G1 and G2.

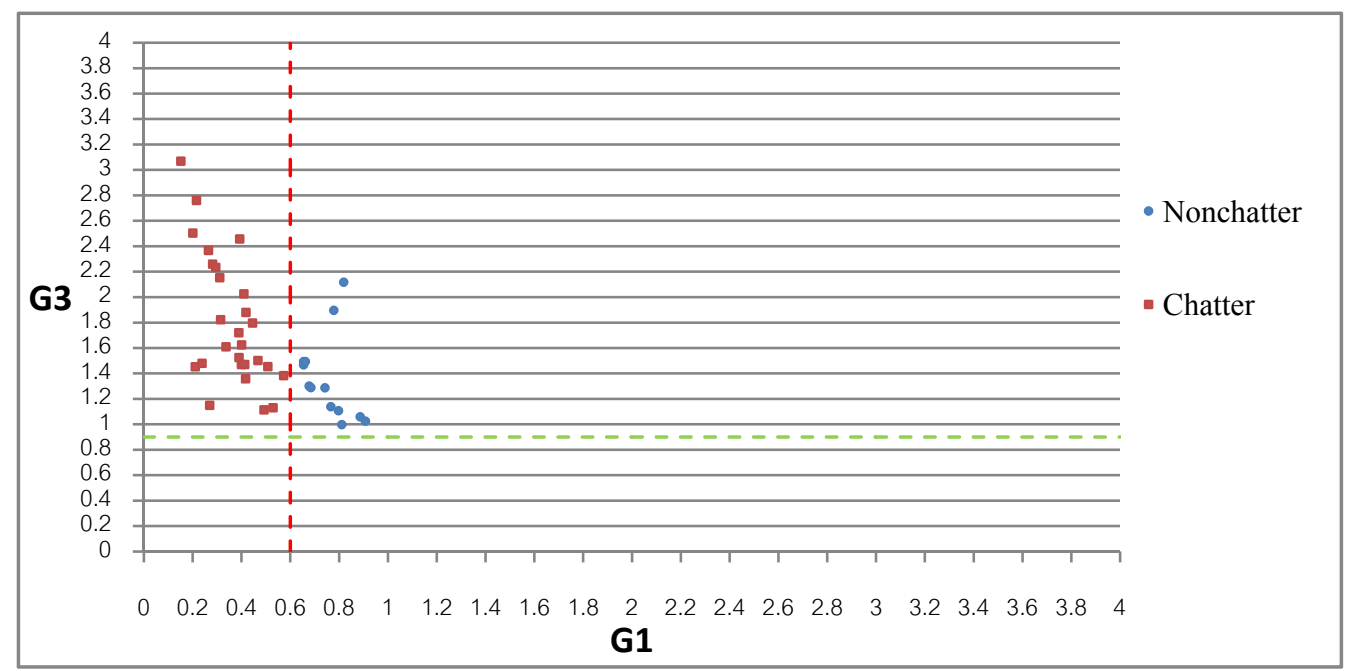

Figure 8. Illustration of the experimentally obtained relation between G1 and G3.

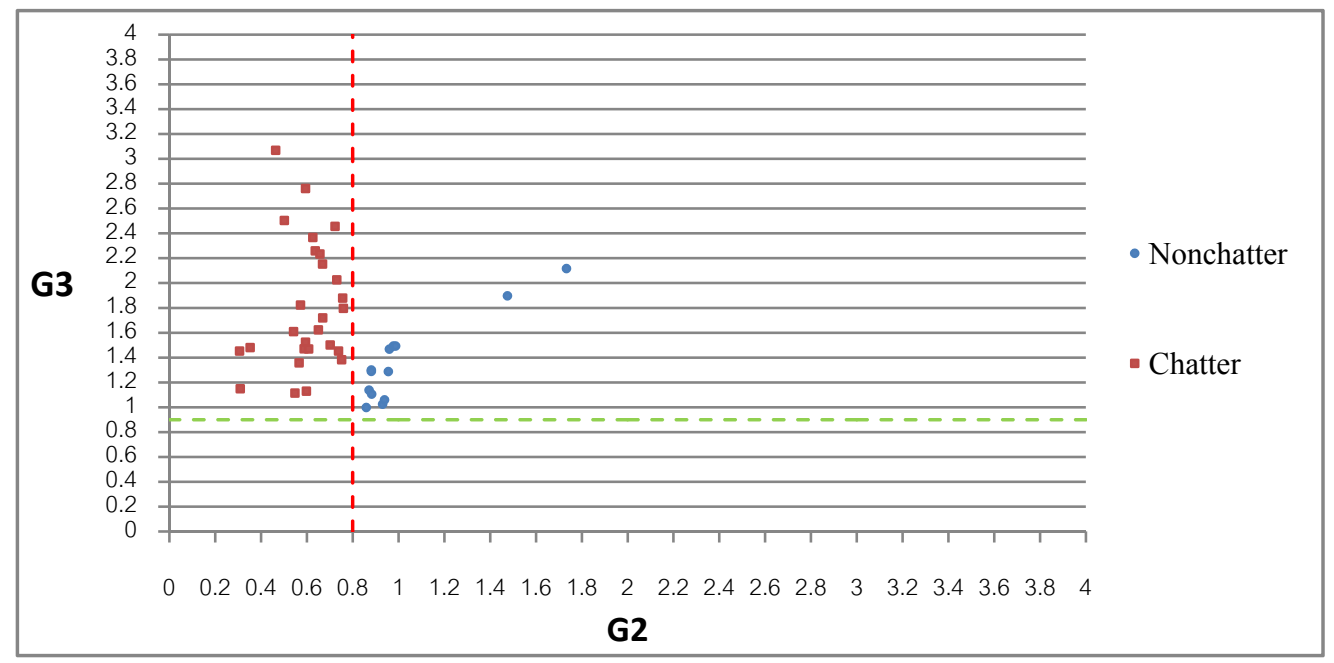

Figure 9. Illustration of the experimentally obtained relation between G2 and G3. 

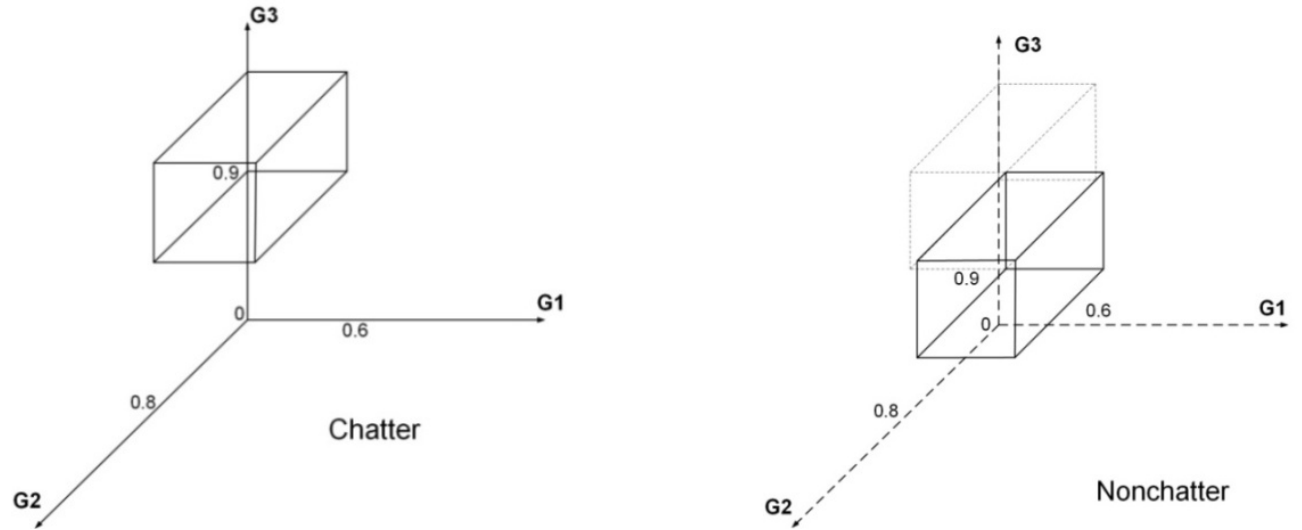

Figure10. Illustration of the experimentally obtained relations of G1, G2, and G3.

\section{Relation of Chatter and Cutting Conditions}

Fig. 11 shows the experimentally obtained relation between G1 and spindle speed under various depths of cut and feed rates. While the chatter occurs, the parameter values of G1 is relatively small as shown in Figs. 11 to 13. It is understood that the higher spindle speed causes the chatter easily due to the vibration of the grinding wheel. However, the chatter occurs at the lower feed rate as shown in Fig. 12 even though the depths of cut and spindle speeds are changed. Since the faster feed rate helps to reduce the friction force which results in the stable grinding. Fig. 13 illustrates that the chatter tends to increase at the larger depth of cut due to the larger cutting force which leads to the vibration of grinding wheel regardless of the spindle speeds and the feed rates.

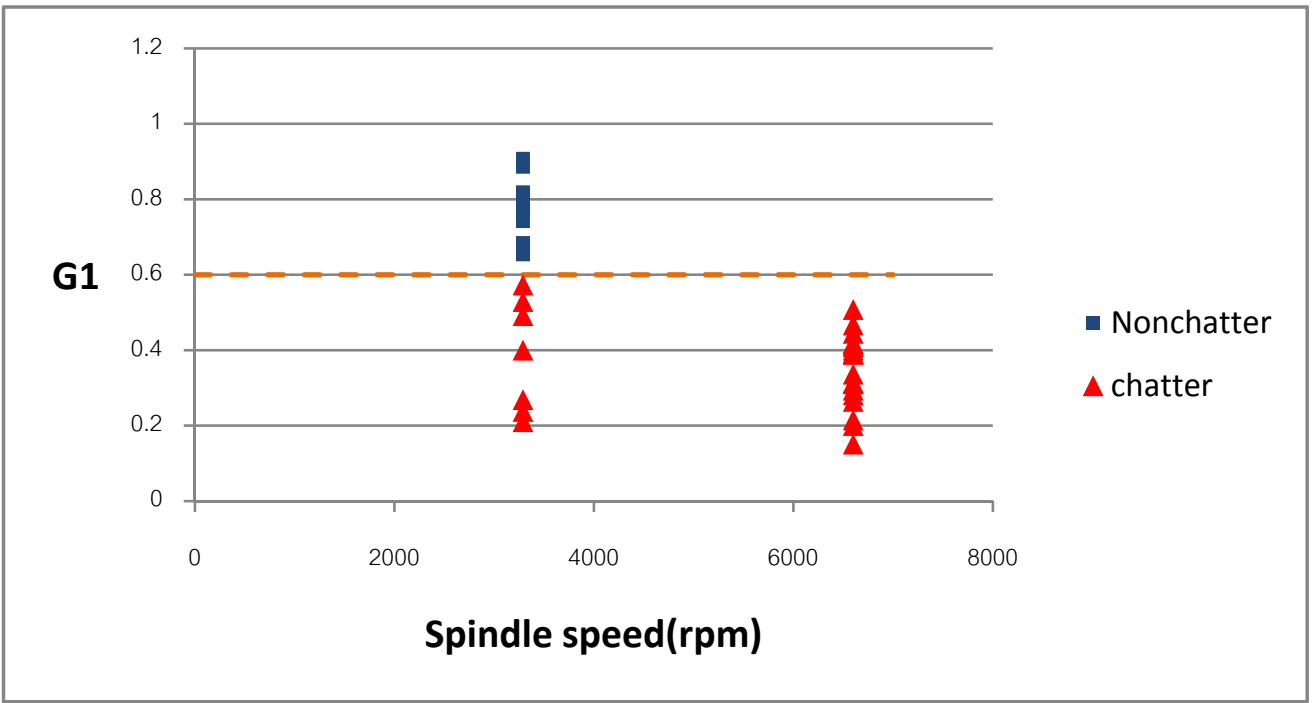

Figure 11. Illustration of the experimentally obtained relation between G1 and spindle speed

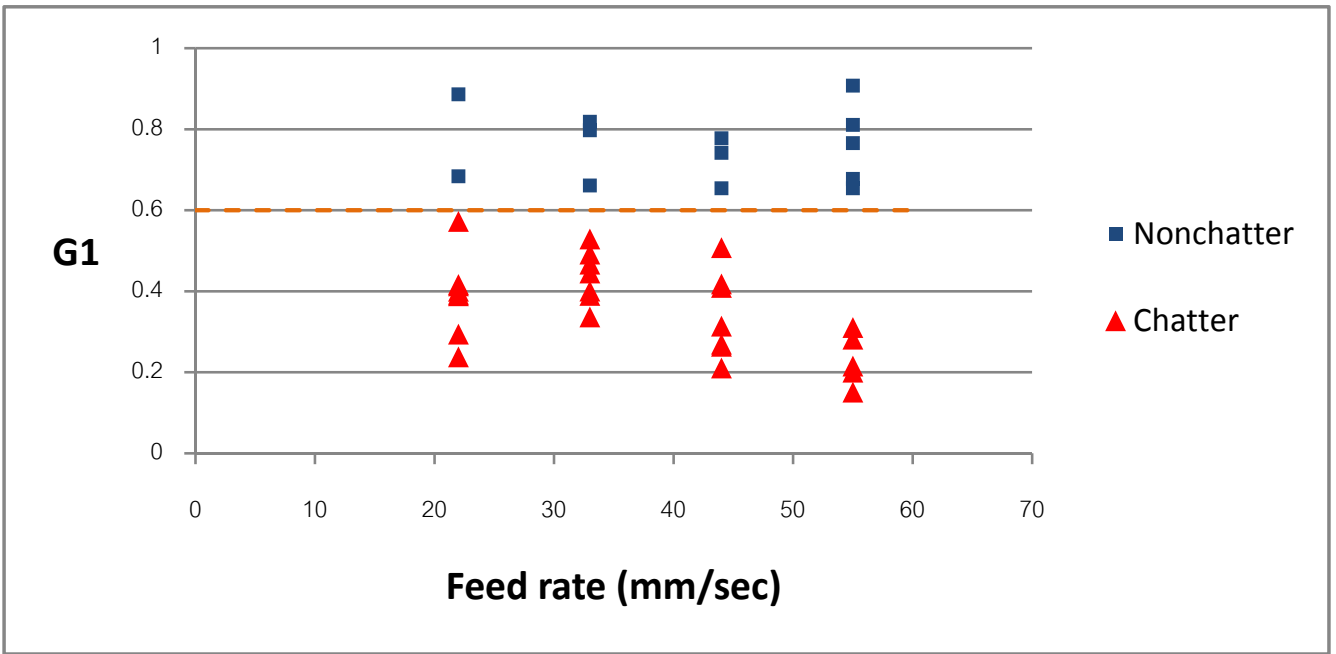

Figure 12. Illustration of the experimentally obtained relation between G1 and feed rate. 


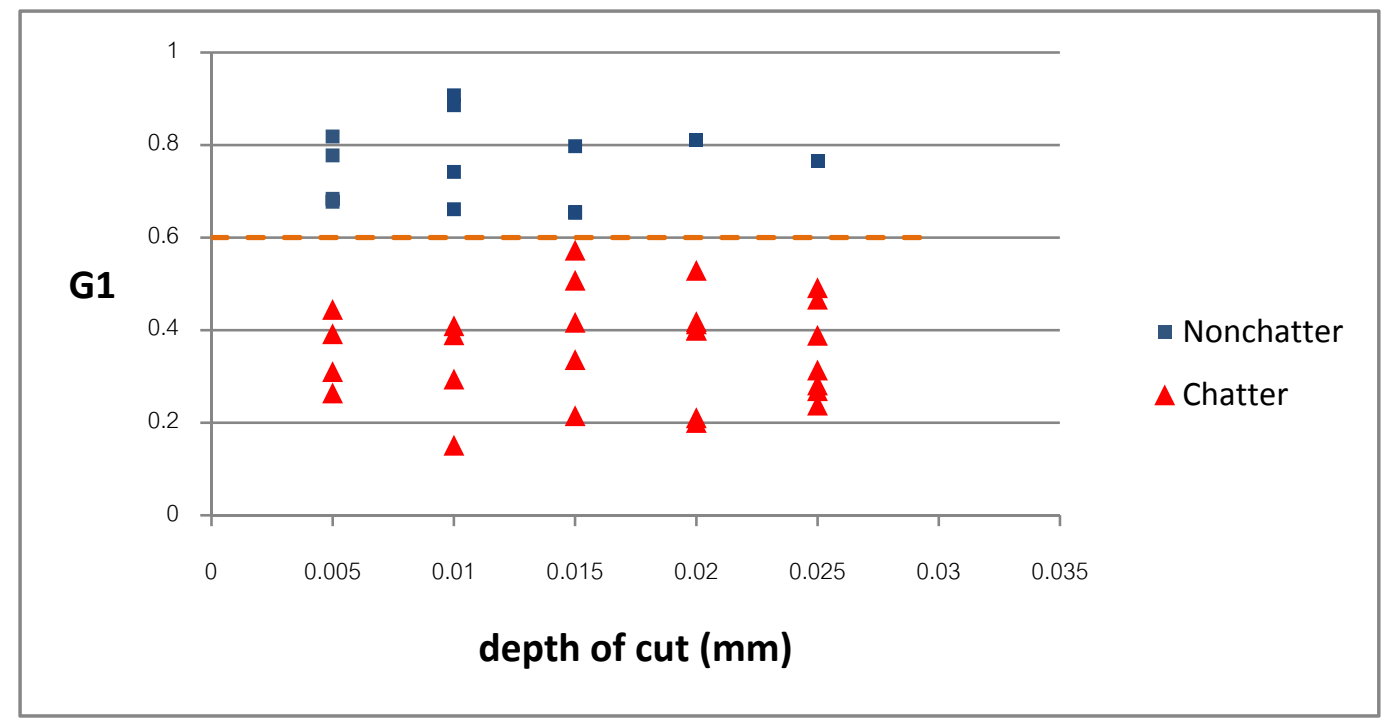

Figure 13. Illustration of the experimentally obtained relation between G1 and depth of cut.

The algorithm is proposed and developed to detect the chatter during the surface grinding process referring to the proper values of $\mathrm{T} 1, \mathrm{~T} 2$, and $\mathrm{T} 3$ as shown in Fig. 14. Fig. 14 also illustrates the algorithm to avoid the chatter using the precaution by decreasing the spindle speed, decreasing the depth of cut, and increasing the feed rate, respectively.

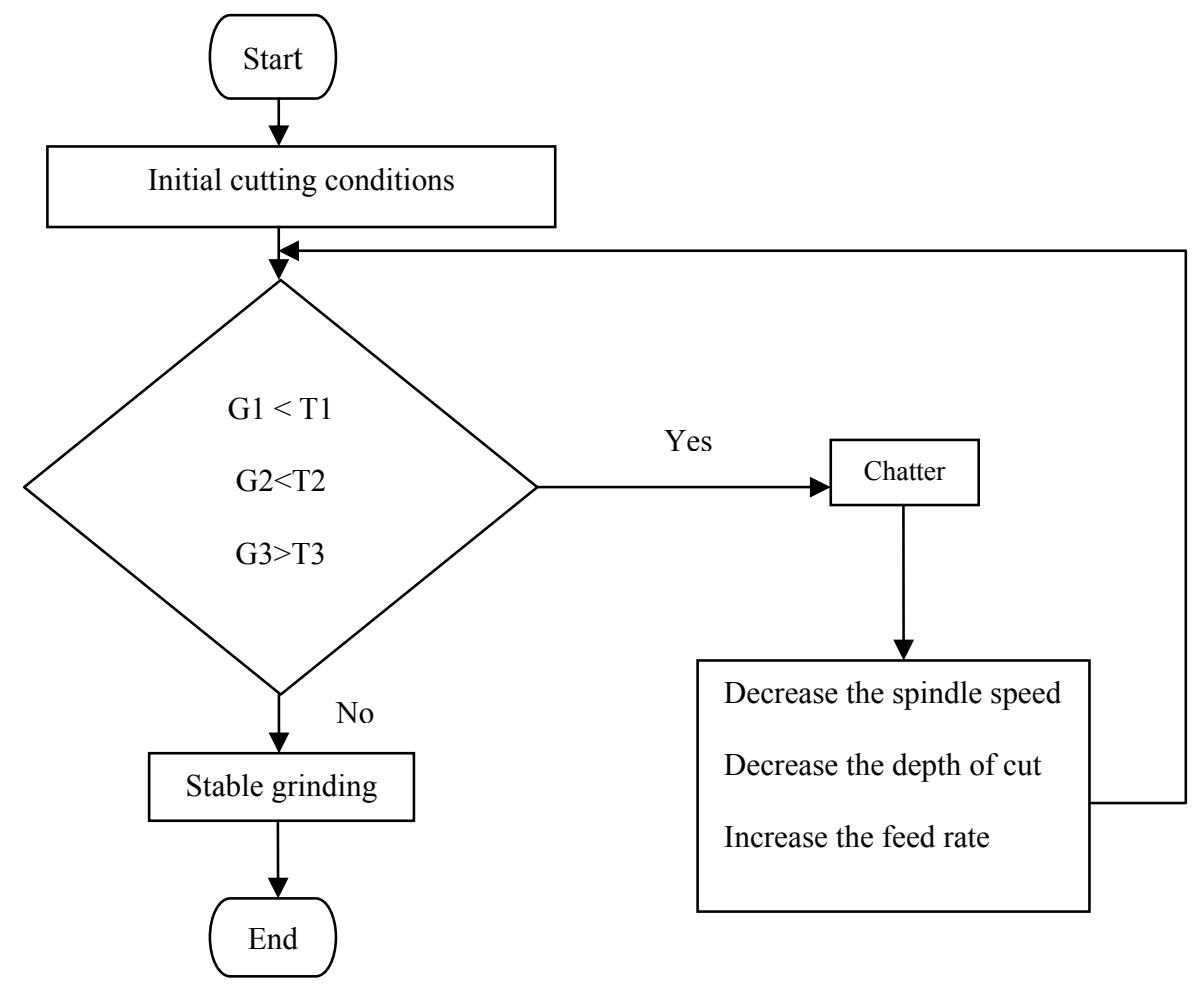

Figure 14. Flowchart to detect and avoid the chatter during the surface grinding process.

The highest advantage of the proposed method is the chatter can be easily detected within the short time of the data processing by simply mapping the obtained values of $\mathrm{G} 1, \mathrm{G} 2$, and $\mathrm{G} 3$ referring to determined critical values of $\mathrm{T} 1, \mathrm{~T} 2$, and $\mathrm{T} 3$ in the reference feature spaces. The proposed method can detect the chatter in time domain, not in the frequency domain such as the FFT method, which can help to reduce the data processing time. As a consequence, the chatter can be effectively avoided within the very short time or real time. However, the proposed method requires the preliminary cutting tests to obtained the critical values of parameters $\mathrm{G} 1=\mathrm{X} / \mathrm{Y}, \mathrm{G} 2=\mathrm{X} / \mathrm{Z}, \mathrm{G} 3=\mathrm{Y} / \mathrm{Z}$. 


\section{Conclusions}

An in-process chatter detection has been proposed and developed for the surface grinding process in order to realize the intelligent machine based on the monitoring of dynamic cutting forces. A previously developed method of the author is adopted to determine the proper values to classify the chatter and the nonchatter by taking the ratio of the average variances of the dynamic cutting forces.

The chatter phenomenon in the surface grinding process usually appears at the high spindle speed, the low feed rate, and the large depth of cut. The algorithm to detect and avoid the chatter is proposed to increase the stability of the surface grinding process by utilizing the precaution. It has been proved by the actual cutting that the chatter is readily detected by the developed method within the very short data-processing time.

The highest advantage of the proposed method is that the chatter and the nonchatter can be detected easily during the in-process grinding regardless of the cutting conditions by simply mapping the experimentally obtained values of parameters G1, G2, and G3 referring to the determined proper values of $\mathrm{T} 1, \mathrm{~T} 2$, and $\mathrm{T} 3$ in the three-dimensional reference feature spaces.

\section{Acknowledgement}

This work was performed and supported by The Automotive Design and Manufacturing Engineering, International School of Engineering, Chulalongkorn University, Thailand 2012-2013.

\section{References}

1. Y. Altintas: Manufacturing automation, principles of metal cutting and machine tool vibrations, Cambribge University (2000), in press.

2. Y. Altintas: Analytical prediction of three dimensional chatter stability in milling, Jpn. Soc. Mech. Eng. Vol. 44(3) (2001), p. 717-723.

3. M. Rahman: In-process detection of chatter by automatic spindle regulation, CIRP Ann Vol. 41(1) (1992), p. 433-436.

4. I. Inasaki, B. Karpuschewski and H.S. Lee: Grinding Chatter - Origin and Suppression, CIRP Ann. Manuf. Technol. Vol. 50(2) (2001), p. 515534.

5. Z.C. Li, B. Lin, Y.S. XU, et al: Experimental studies on grinding forces and force ratio of the unsteady-state grinding technique, J. Mater. Process. Technol. Vol. 129(1-3) (2002), p. 76-80.

6. H. Li and Y.C. Shin: A study on chatter boundaries of cylindrical plunge grinding with process condition-dependent dynamics, Int. J. Mach. Tool Manuf. Vol. 47 (2007), p. 1563-1572.

7. N. Subramanya and Y.C. Shin. Automated sensor selection and fusion for monitoring and diagnostics of plunge grinding, Trans. ASME J. Manuf. Sci. Eng. Vol. 130(3) (2008), 031014-1 031014-11.
8. Y. Altintas and P. Lee: Mechanics and dynamics of ball end milling, Trans. ASME J. Manuf. Sci. Vol. 120 (1998), p. 684-692.

9. Y. Altintas and E. Budek: Analytical prediction of stability lobes in milling, Ann CIRP Vol. 44(1) (1995), p. 357-362.

10. Y. Altintas and S.S. Park: Dynamic Compensation of Spindle- Integrated Force Sensors, Ann CIRP Vol. 53(1) (2004), p. 305-308.

11. S. Tangjitsitcharoen and T. Moriwaki: Intelligent identification of turning process based on pattern recognition of cutting states, Mater. Proc. Technol. Vol. 192-193 (2007), p. 491-496.

12. J. Hino, C. Su and T. Yoshimura: A study of chatter prediction in high-speed end milling process by fuzzy neural network, J. Soc. Mech. Eng. Ser.C Vol. 47 (2001), p. 825-831.

13. T. Moriwaki and Y. Mori: Sensor fusion for inprocess identification of cutting process based on neural network approach, Proc. IMACS/SICE Int. Symp. on Rob, Mechatron. and Manuf. Syst. Kobe (1992), p. 245-250.

14. S. Tangjitsitcharoen: Advance in detection system to improve the stability and capability of $\mathrm{CNC}$ turning process, J. Intell. Manuf. Vol. 22 (2011), p. 843-852.

15. K. Ueda, S. Miyamoto and T. Sugita: An approach to adaptive control based on pattern recognition of cutting states, In: Proceedings of 6th International Conference Production Engineering, Osaka (1987), p. 212-217.

16. S. Tangjitsitcharoen and N. Pongsathornwiwat: Development of chatter detection in milling process, Int. J. Adv. Manuf. Technol. Vol. 65 (2013), p. 919-927.

17. T. Sata, K. Matsushima, T. Nakamura, et al: Learning and recognition of the cutting states by spectrum analysis, Ann CIRP Vol. 22 (1973), p. 41-42. 